\title{
Sedimentation of Magnetic Suspensions of Magnetite
}

\author{
X. Yang and C. Aldrich*
}

Department of Process Engineering, University of Stellenbosch, Private Bag X1, Matieland, Stellenbosch 7602, South Africa

\begin{abstract}
The gravity sedimentation of three narrow-sized fractions of suspensions of magnetite particles exposed to magnetic fields ranging from 0 to $180 \times 10^{-4} \mathrm{~T}$ was studied experimentally. At volumetric solids concentrations in excess of $15 \%$, the magnetized suspensions of magnetite with size fractions ranging from -75 to $+38 \mu \mathrm{m}$ settled more slowly than the non-magnetized suspensions. However, owing to relatively weak magnetic interaction, the sedimentation of the magnetized and non-magnetized $-38 \mu \mathrm{m}$ size fractions was similar.
\end{abstract}

\section{INTRODUCTION}

Natural magnetite is usually separated by wet lowintensive magnetic methods. Likewise, separation of magnetic slime particles can be improved by magnetic flocculation, which reduces the cost of dewatering by increasing the settling velocity of solids and improving the filtration rates of ferromagnetic products. The settling of magnetite is similarly an issue where magnetite suspensions in external magnetic fields are used as heavy media in the gravity separation of minerals and in coal preparation. Settling of these magnetic suspensions affects the efficiency of the processes, where good stability and low viscosity of the heavy media are required. Sedimentation of particles in concentrated suspensions has been investigated extensively. There are many theoretical and experimental correlations for predicting the settling velocity of particles as a function of solid concentration for monodisperse suspensions. One of the most popular is the correlation proposed by Richardson and Zaki [1], given by

$$
\mathrm{U}_{\mathrm{s}} / \mathrm{U}_{\mathrm{t}}=(1-\phi)^{\mathrm{n}-1}
$$

or

$$
\mathrm{U}_{\phi} / \mathrm{U}_{\mathrm{t}}=(1-\phi)^{\mathrm{n}}
$$

The exponent $\mathrm{n}$ depends on the Reynolds number of the particle $\left(\operatorname{Re}=\rho U_{t} d / \eta\right)$ and the ratio of the particle size to the geometry of the settling vessel $(\mathrm{d} / \mathrm{D})$, that is $\mathrm{n}=4.85+$ $19.5(\mathrm{~d} / \mathrm{D})$, for $0<\operatorname{Re}_{\infty}<0.2$ and $\mathrm{n}=[4.35+17.5(\mathrm{~d} / \mathrm{D})] \mathrm{Re}_{\infty}{ }^{-}$ ${ }^{0.03}$, for $0.2<\operatorname{Re}_{\infty}<1.0$. Garside and Al-Dibouni [2] suggested the following expression:

$$
(5.1-n) /(n-2.7)=\operatorname{Re}^{0.9} / 10
$$

Owing to effect of the container walls on settling, the terminal velocity in finite fluid $U_{t}$ rather than $U_{t, \infty}$ is used in eq. 1 and 2. The following expressions which relate $U_{t}$ to $\mathrm{U}_{\mathrm{t}, \infty}$ were recommended by Garside and Al-Dibouni [2].

$\mathrm{U}_{\mathrm{t} \infty} / \mathrm{U}_{\mathrm{t}}=\{[1-0.475(\mathrm{~d} / \mathrm{D})] /[1-(\mathrm{d} / \mathrm{D})]\}^{4}$

\footnotetext{
*Address correspondence to this author at the Department of Process Engineering, Private Bag X1, Matieland, 7602, Stellenbosch, South Africa; Fax: +27(21)8082059; Tel: +27(21)8084487/4712;
}

E-mails: ca1@sun.ac.za, aldrich@mweb.co.za for $\operatorname{Re}<0.2$

$\mathrm{U}_{\mathrm{t}, \infty} / \mathrm{U}_{\mathrm{t}}=1+2.35(\mathrm{~d} / \mathrm{D})$

for $0.2<\operatorname{Re}<1000$

$\mathrm{U}_{\mathrm{t}, \alpha} / \mathrm{U}_{\mathrm{t}}=1 /\left[1-(\mathrm{d} / \mathrm{D})^{3 / 2}\right]$

for $1000<\operatorname{Re}<3000$

Felice and Parodi [3] investigated the relation of $\mathrm{U}_{\mathrm{t}, \infty} / \mathrm{U}_{\mathrm{t}}$ and $n$ to the container wall effect represented by $d / D$ and concluded that for concentrated systems both $\mathrm{U}_{\mathrm{t}, \infty} / \mathrm{U}_{\mathrm{t}}$ and $\mathrm{n}$ are independent of $d / D$. Michaels and Bolger [4] analysed the sedimentation of flocculated suspensions by replacing the solid concentration $\phi$ in eq. 2 by an effective volume fraction $\kappa \phi$, which represents particle aggregates and entrapped fluid in the interstitial space. The more complex the particle shape, the higher the value of $\kappa(>1)$. Turian et al. [5] used the following expression to represent the sedimentation of narrow-sized coal suspensions: $\mathrm{U}_{\phi} / \mathrm{U}_{\mathrm{t}}=(1-\mathrm{k} \phi)^{4.68}$ and found that the value of $\mathrm{k}$ varies between 1.15 to 1.2 for different narrow size fractions. Sedimentation of binary and polydisperse concentrated suspensions were studied by a number of authors [6-13] using colloid and noncolloid particles. In addition, some new techniques have been used to measure the settling velocity of particles in suspensions. Computer tomography was used by Auzerais et al. [14] to study the sedimentation of monodisperse colloidal silica spheres. Turney et al. [15] used magnetic resonance imaging to measure the time evolution of volume fraction versus height profile during sedimentation of rod-like particle suspensions. Vergouw et al. [16] developed a conductivitybased technique for automatically recording settling data by measuring conductance as particles settle through a conductivity cell, which they have used to study the sedimentation of pyrite and sphalerite suspensions. Fewer papers were published on the sedimentation of magnetic suspensions. Svoboda et al. [17-19] have analysed magnetic flocculation of fine $(1-40 \mu \mathrm{m})$, weakly magnetic minerals, by considering magnetic interaction in DVLO theory. Ganzha and Saxena [20] investigated the hydrodynamic behaviour of magnetically stabilised fluidised beds of magnetic particles. They have observed that in sufficiently strong external magnetic fields, the presence of magnetized particles in the bed could lead to significant distortion of the external uniform field, 
appreciable interparticle forces and more complex hydrodynamics behaviour. However, sedimentation as such was not considered in any of these studies and in this paper, the effect of an external magnetic field on the settling of magnetite particles of different sizes and concentrations is considered.

\section{EXPERIMENTAL WORK}

Experiments were conducted with magnetite concentrate from a mine in South Africa that mainly consisted of magnetite, quartz, manganese oxide and pyrite. The material was separated by sieving into four size fractions, viz. $+75 \mu \mathrm{m}$, $75+53 \mu \mathrm{m},-53+38 \mu \mathrm{m}$ and $-38 \mu \mathrm{m}$. The last three fractions of $-75+53 \mu \mathrm{m},-53+38 \mu \mathrm{m}$ and $-38 \mu \mathrm{m}$ were used in sedimentation experiments. The size distributions of the fractions and the specific surface area were obtained by using a Malvern size analyser and a Micromeritics ASAP 2010 respectively. The density of the samples was analysed by a Micromeritics pycnometer. The maximum packing weight $\left(\mathrm{C}_{\mathrm{m}}\right)$ and volume fraction $\left(\phi_{\mathrm{m}}\right)$ were calculated at the completion of sedimentation after approximately 30 to 60 minutes. The mean diameter $d_{\text {mean }}$ of samples was calculated by $d_{\text {mean }}=$ $\Sigma \gamma_{\mathrm{i}} \mathrm{d}_{\mathrm{i}} / 100$, where $\mathrm{d}_{\mathrm{i}}, \gamma_{\mathrm{i}}$ is the diameter and the weight cumulative fraction of the i'th particle species respectively. The properties of the experimental samples are summarized in Table 1. All suspensions were made up by using distilled water and settling experiments were carried out in $100 \mathrm{~mL}$ $(\mathrm{D}=2.90 \mathrm{~cm})$ and $500 \mathrm{~mL}(\mathrm{D}=4.94 \mathrm{~cm})$ graduated measurement cylinders at temperatures ranging from 17 to $20^{\circ} \mathrm{C}$. The magnetite suspensions were placed in plastic containers in uniform adjustable external magnetic fields with strengths ranging from 0 to $180 \times 10^{-4} \mathrm{~T}$. The suspensions were removed from the plastic containers after two minutes of exposure to the uniform magnetic field and placed into the measurement cylinders. The settling rate of the suspensions was determined by recording the height of the interface between the clear liquid and the suspension at different times.

Table 1. Properties of Experimental Samples

\begin{tabular}{|c|c|c|c|}
\hline Property & $\mathbf{- 7 5 + 5 3} \boldsymbol{\mu \mathbf { m }}$ & $\mathbf{- 5 3 + 3 8} \boldsymbol{\mu} \mathbf{m}$ & $\mathbf{- 3 8} \boldsymbol{\mu \mathbf { m }}$ \\
\hline \hline$\rho_{\mathrm{s}}\left(\mathrm{kg} \cdot \mathrm{m}^{-3}\right)$ & 4700 & 4790 & 4680 \\
\hline $\mathrm{C}_{\mathrm{m}}(\mathrm{w} / \mathrm{w})$ & 0.75 & 0.74 & 0.70 \\
\hline$\phi_{\mathrm{m}}(\mathrm{v} / \mathrm{v})$ & 0.39 & 0.37 & 0.33 \\
\hline $\mathrm{d}_{\text {mean }}(\mu \mathrm{m})$ & 59.2 & 42.4 & 35.2 \\
\hline $\mathrm{d}_{50}(\mu \mathrm{m})$ & 39.5 & 36.4 & 25.5 \\
\hline $\mathrm{S}\left(\mathrm{m}^{2} / \mathrm{g}\right)$ & 1.833 & 1.842 & 3.079 \\
\hline
\end{tabular}

\section{RESULTS AND DISCUSSION}

\section{Sedimentation in the Absence of an External Magnetic Field}

Sedimentation experiments of non-magnetized magnetite suspensions were performed in a $500 \mathrm{~mL}$ cylinder with a $4.94 \mathrm{~cm}$ inner diameter. The cylinder was filled and the solids dispersed by repeatedly inverting the cylinder. The settling height versus time curves of the different size fractions are shown in Figs. (1-3). Fig. (1) indicates that the $-75+53$ $\mu \mathrm{m}$ fraction settled rapidly and settling rates of all volumetric concentrations ranging from 0.084 to 0.242 were more or less invariant during the entire settling process, which resulted in relatively incompressible final sediment. In contrast, the settling curves of all concentrations for the $-38 \mu \mathrm{m}$ fraction shown in Fig. (3) suggest progressively decreasing settling rates and relatively compressible final sediments. For the intermediate $-53+38 \mu \mathrm{m}$ fraction shown in Fig. (2), sedimentation at volumetric concentrations in excess of 0.146 is similar to that of the $-38 \mu \mathrm{m}$ fraction, i.e. decreased settling with time, resulting in a compressible final sediment, while sedimentation at volumetric concentrations less than 0.146 is similar to that of the $-75+53 \mu \mathrm{m}$ fraction, i.e. rapid invariant settling, resulting in an incompressible final sediment. The observations on the sedimentation of the suspensions containing different particle size fractions confirm that the forces between the particles of the $-38 \mu \mathrm{m}$ size fraction are strong, leading to flocculation regardless of concentration.

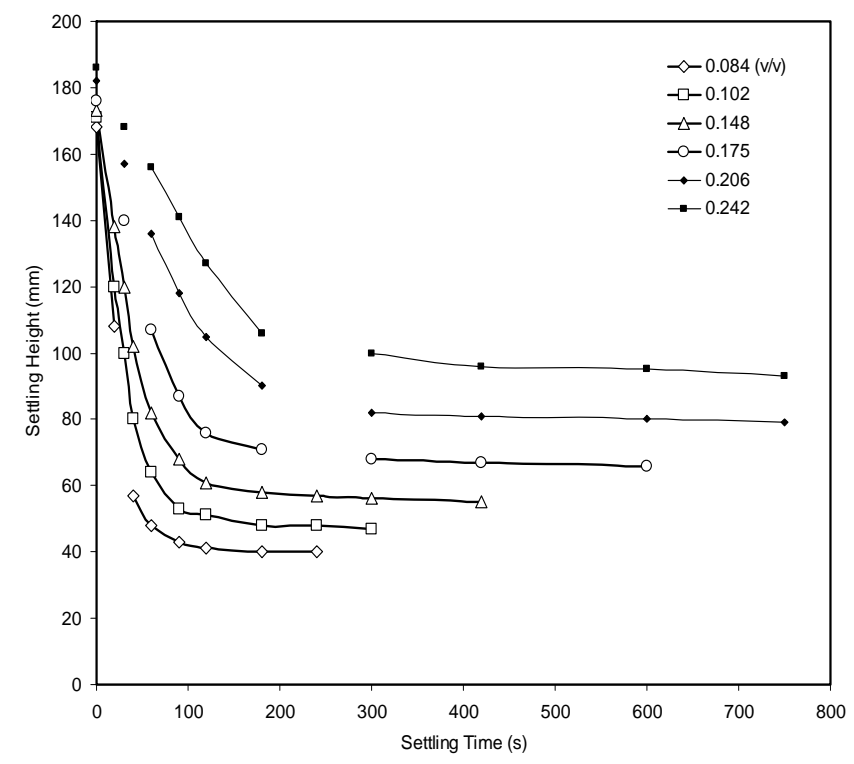

Fig. (1). Settling rates of different volumetric concentrations of $-75+53 \mu \mathrm{m}$ suspensions.

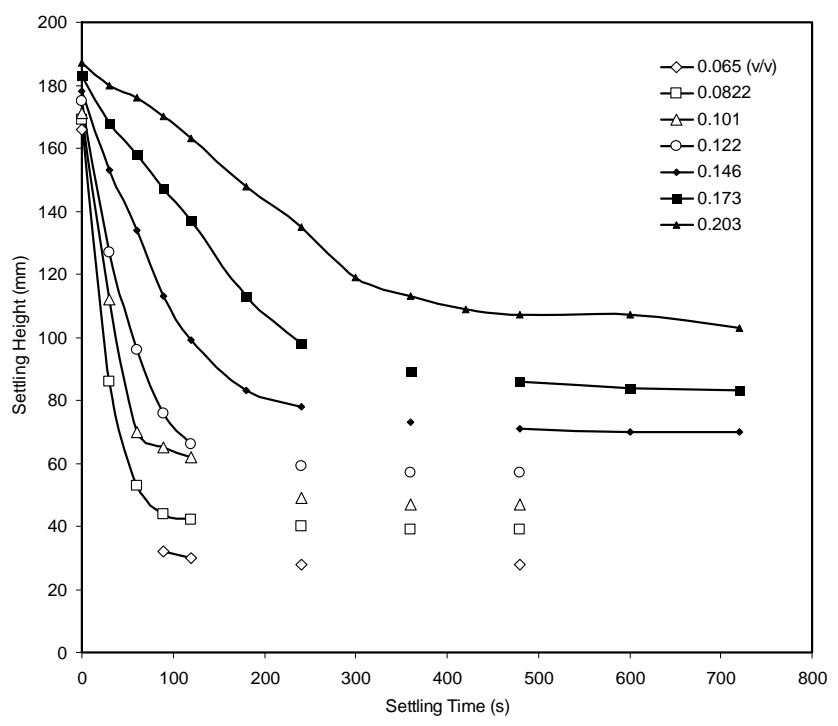

Fig. (2). Settling rates of different volumetric concentrations of $-53+38 \mu \mathrm{m}$ suspensions. 


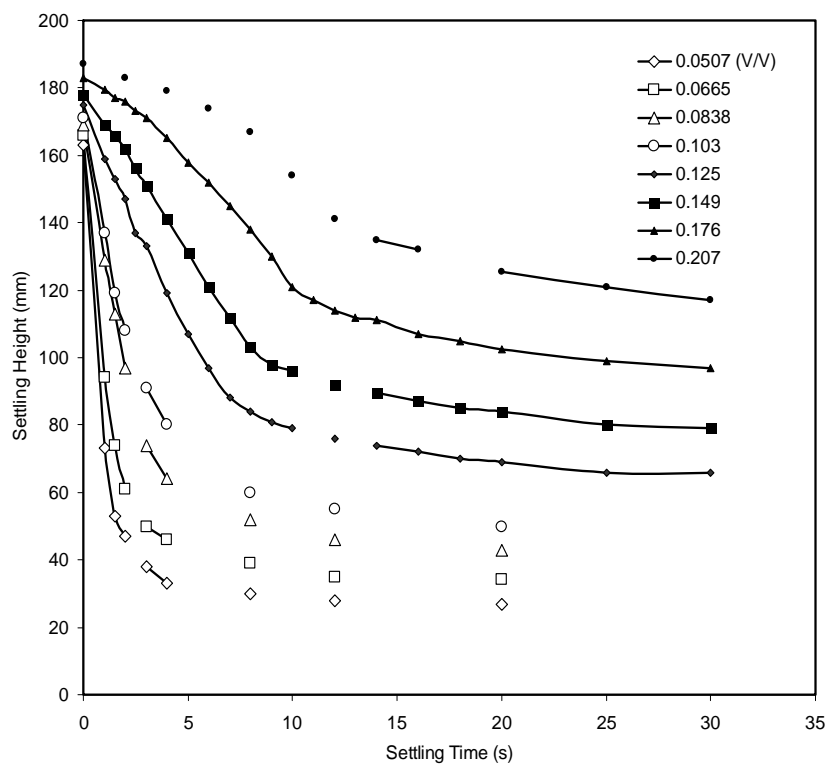

Fig. (3). Settling rates of different volumetric concentrations of -38 $\mu \mathrm{m}$ suspensions.

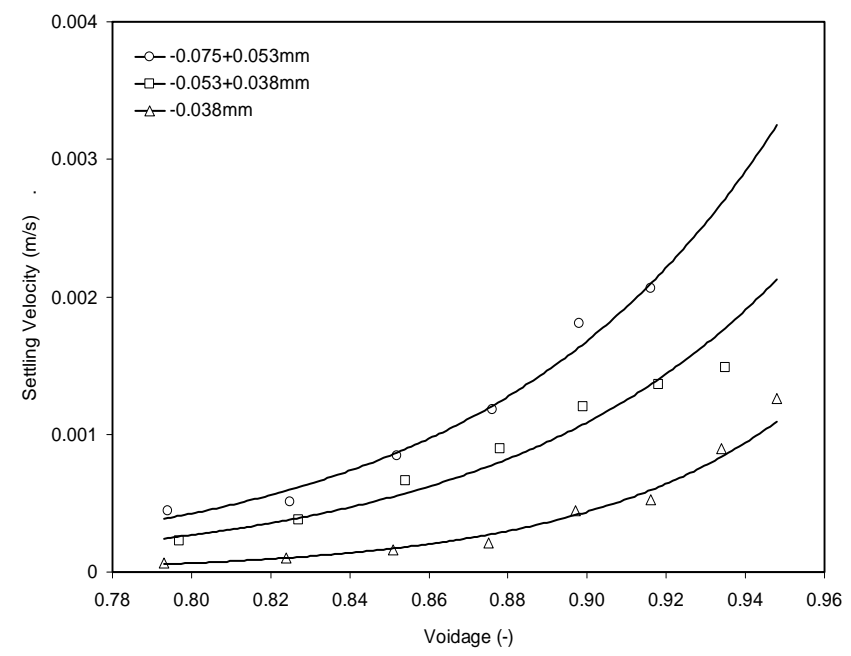

Fig. (4). The influence of suspension voidage on the settling velocity of different size fractions of magnetite.

For the $-75+53 \mu \mathrm{m}$ size fraction the interacting forces between particles are weak compared to gravity and can be neglected. In the case of the $-53+38 \mu \mathrm{m}$ particles, the net effect depends on the concentration of the suspension. The plots of settling velocity $U_{\phi}$ versus voidage 1- $\phi$ for the three size fractions are shown in Fig. (4).

These results in $\mathrm{m} / \mathrm{s}$ can be correlated by least square fits as follows, with $\mathrm{R}^{2}=0.97, \mathrm{R}^{2}=0.98, \mathrm{R}^{2}=0.98$, for eqs $7-9$ respectively.

$-75+53 \mu \mathrm{m}: \mathrm{U}_{\phi}=0.0058(1-\phi)^{11.72}$

$-53+38 \mu \mathrm{m}: \mathrm{U}_{\phi}=0.0039(1-\phi)^{12.15}$

$-38 \mu \mathrm{m}: \mathrm{U}_{\phi}=0.0025(1-\phi)^{16.56}$

Equations 7-9 have the same form as that of Richardson and Zaki (eq. 2). To compare the experimental data with calculated results we consider the parameters of 0.0058 , 0.0039 and 0.0025 in eq. $7-9$ to be the experimental terminal velocities $U_{t, \exp }$ of the three respective particle size fractions.
They were subsequently modified according to eq. 3 to account for the container wall effects to obtain the experimental terminal velocities of the single particles in an infinite fluid $U_{t, \infty, \text { exp }}$. Since the particles are sufficiently fine to ensure laminar flow conditions, we can use Stokes' law

$\mathrm{U}_{\mathrm{t}, \infty}=\left(\rho_{\mathrm{s}}-\rho\right) \operatorname{gd}_{\mathrm{St}}{ }^{2} / 18 \mu$

to calculate the terminal velocity in an infinite fluid and then get $U_{t}$ by accounting for the effects of the walls of the container. We used the mean diameter $d_{\text {mean }}$ to approximate the Stokes diameter $d_{S t}$ in eq. 10 in the calculation of the terminal velocities of the three size fractions in the fluid, $U_{t, \infty, \text { calc }}$ and $U_{t, \text { calc }}$. We have also calculated the values of the exponent $\mathrm{n}$ in the Garside-Al-Dibouni (eq. 3) and Richardson-Zaki equations (eq. 2). Table 2 summarizes the experimental and calculated values of $U_{t}$ and $n$. From Table 2 it can be seen that the experimental and calculated values of $U_{t}$ are close, that is the sedimentation of the samples agree well with the Richardson-Zaki model. In addition, as can be seen from Table 3 , the values of exponent $n$ obtained from the experimental data are markedly higher than the ones calculated from the Garside-Al-Dibouni and Richardson-Zaki equations, especially for the $-38 \mu \mathrm{m}$ particle suspensions. These discrepancies can in part be attributed to the nonspherical shapes of the particles. Chong et al. [21] have found $n$ to be about 4.8 for spheres, 5.4 for cubic shapes, and 5.8 for brick-like and angular particles and have suggested that particle interaction is increased with increased asphericity in the particles, which in turn results in increased retardation of the settling rate. Turney et al. [15] have studied the hindered settling of rod-like particles and found that as the volume fractions increased, the hindered settling $\mathrm{U}_{\phi} / \mathrm{U}_{t}$ of rod-like particles was more strongly dependent on volume fraction than that of spherical particles. They attributed this to the stronger forces acting between nonspherical particles compared to those acting between spherical particles, as well as the larger viscosities of the nonspherical particle suspensions. Both factors tend to reduce the sedimentation velocity of nonspherical particle suspensions. In addition, it is also possible that the particles could have formed agglomerates, trapping water, which could have led to a lower effective void fraction in the fluid. Similar studies by Mercer et al., [22] albeit with very fine magnetite, have suggested that this could result in very large deviations in the exponent of the Richardson-Zaki model.

Table 2. Settling Parameters for Different Size Fractions

\begin{tabular}{|c|c|c|c|c|c|}
\hline \multirow{2}{*}{$\begin{array}{c}\text { Size } \\
\text { Fract } \\
(\boldsymbol{\mu} \mathbf{m})\end{array}$} & \multicolumn{3}{|c|}{$\mathbf{N 3}$} & \multirow{2}{*}{$\begin{array}{c}\mathbf{U}_{\text {t,exp }} \\
(\mathbf{m m})\end{array}$} & $\begin{array}{c}\mathbf{U}_{\text {t,calc }} \\
(\mathbf{m m} / \mathbf{s})\end{array}$ \\
\cline { 2 - 5 } & $(\mathbf{G A})$ & $\begin{array}{c}\text { Eq. 2 } \\
(\mathbf{R Z )}\end{array}$ & $\begin{array}{c}\text { Exp } \\
\text { data }\end{array}$ & & \\
\hline \hline$-75+53$ & 4.76 & 4.38 & 11.72 & 5.8 & 7.1 \\
\hline$-53+38$ & 4.91 & 4.38 & 12.15 & 3.9 & 3.7 \\
\hline-38 & 5.04 & 4.37 & 16.56 & 2.5 & 2.4 \\
\hline
\end{tabular}

\section{SEDIMENTATION IN THE PRESENCE OF AN EX- TERNAL MAGNETIC FIELD}

Sedimentation experiments with magnetized suspensions with different particle sizes in external magnetic fields rang- 
ing from $\mathrm{B}=0$ to $\mathrm{B}=179.2 \times 10^{-4} \mathrm{~T}$ were carried out in 100 $\mathrm{mL}$ cylindrical containers. The sedimentation rate curves are shown in Figs. (5-7).

For the $-75+53 \mu \mathrm{m}$ and $-53+38 \mu \mathrm{m}$ size fractions the sedimentation of magnetized and non-magnetized suspensions differs significantly. At high concentrations $(\phi>0.17)$ the magnetized suspensions show low settling velocities, resulting in compressible sediment. In contrast, Fig. (7) suggests that for the $-38 \mu \mathrm{m}$ size fraction, exposure to an external magnetic field of $179.2 \times 10^{-4} \mathrm{~T}$ made little difference to

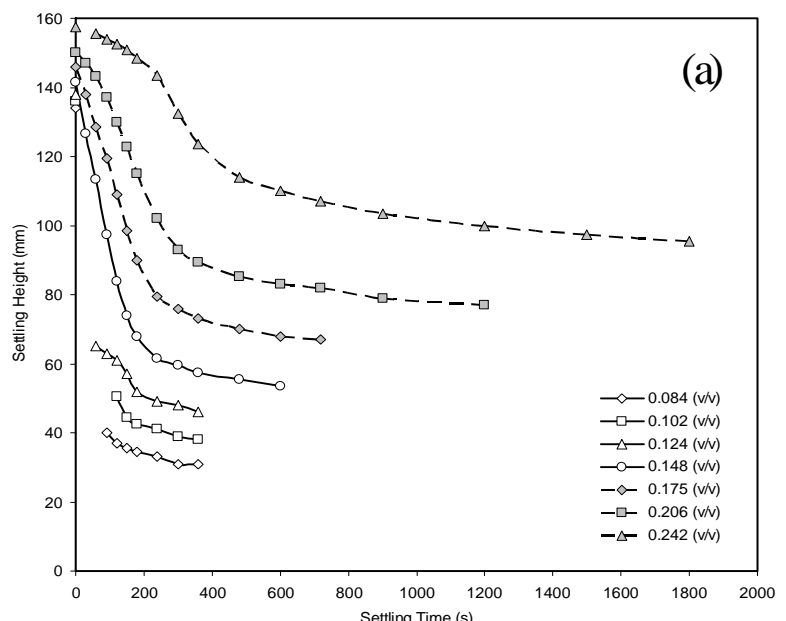

the settling of the particles. The settling velocity versus the voidage of the magnetized suspensions for different size fractions is shown in Fig. (8).

As indicated in Fig. (8), magnetized suspensions settled faster at low concentrations $(\phi<0.15)$ than non-magnetized suspensions of comparable concentration, but slower at high concentrations, the extent of which depended on particle size. In the magnetic field, the particles in suspension become polarized and aggregate. At low concentrations the distances between particles are longer on average and the

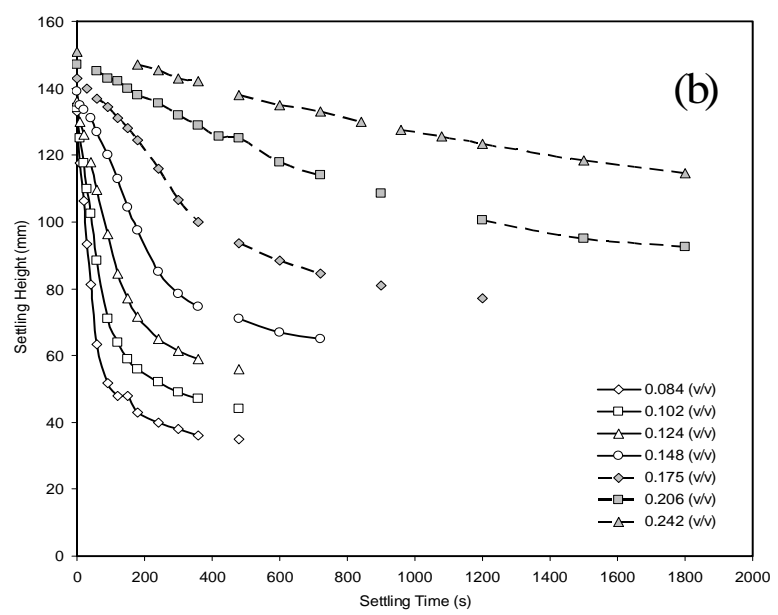

Fig. (5). Sedimentation curves of $-75+53 \mu \mathrm{m}$ size fractions of magnetite in (a) the absence of an external magnetic field suspensions, and (b) an external magnetic field with $\mathrm{B}=179.2 \times 10^{-4} \mathrm{~T}$.
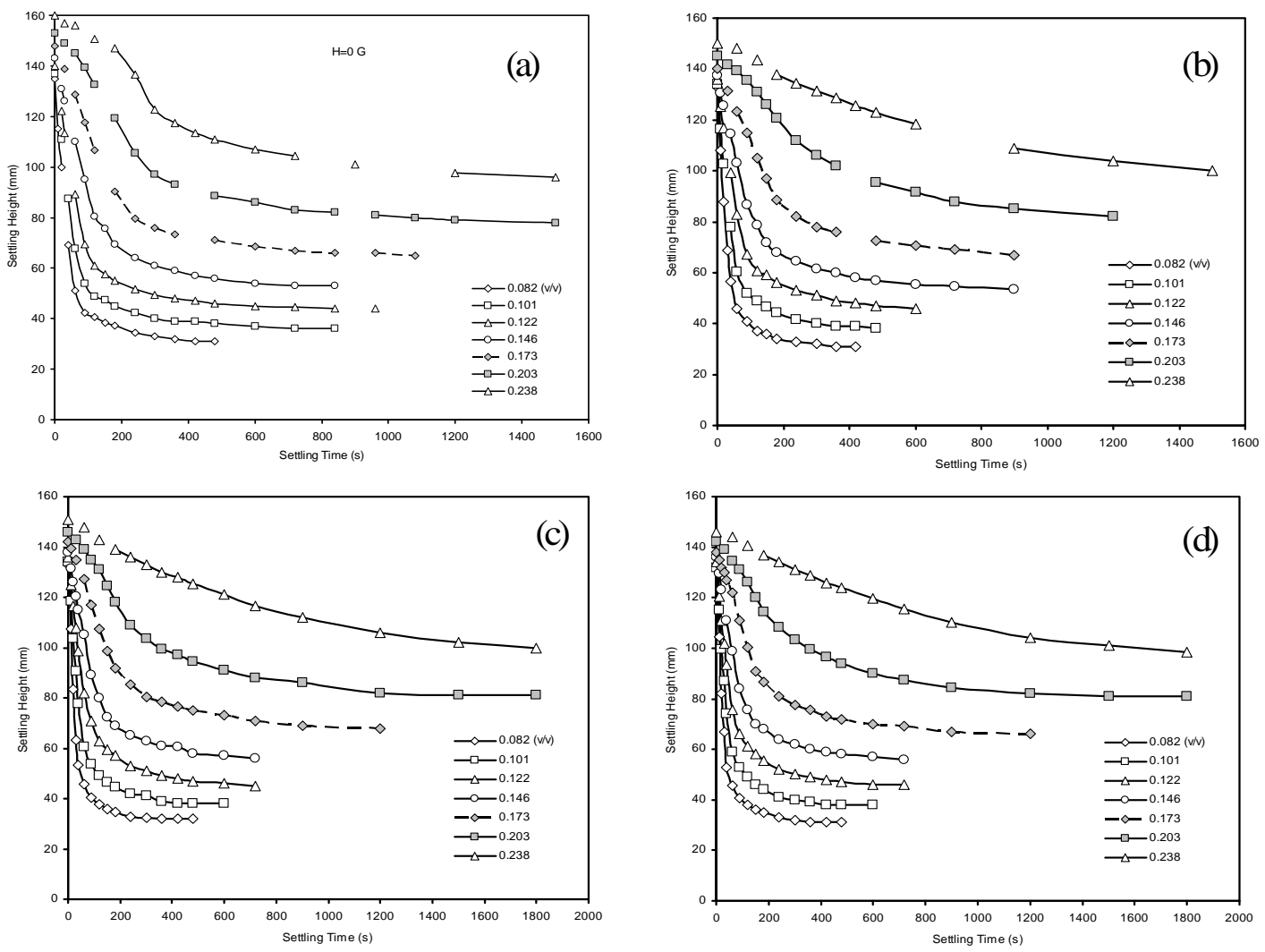

Fig. (6). Sedimentation of the $-53+38 \mu \mathrm{m}$ size fractions in magnetic fields of different strengths: (a) $\mathrm{B}=0,(\mathbf{b}) \mathrm{B}=41.2 \times 10^{-4} \mathrm{~T},(\mathbf{c}) \mathrm{B}=113$ $\mathrm{x} 10^{-4} \mathrm{~T}$ and (d) $\mathrm{B}=179.2 \times 10^{-4} \mathrm{~T}$. 

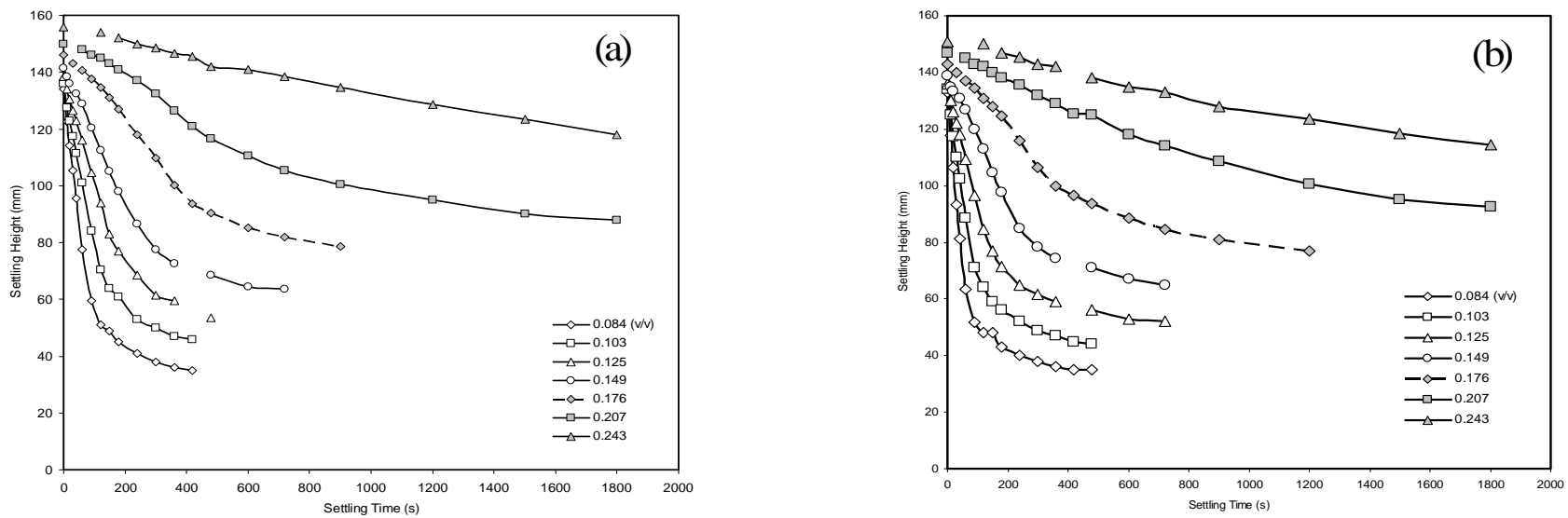

Fig. (7). Sedimentation of the $-38 \mu \mathrm{m}$ size fraction in (a) the absence of an external magnetic field and (b) the presence of a magnetic field of strength $\mathrm{B}=179.2 \times 10^{-4} \mathrm{~T}$.

flocculated particles can settle at a higher rate under gravity. At high concentrations the average distance between particles decreases, which also decreases the space in which separate settling of the flocculated particles can take place. Moreover, owing to orientated attractive forces, the magnetized particles are able to form long chains, which settle markedly slower. For the $-75+53 \mu \mathrm{m}$ and $-53+38 \mu \mathrm{m}$ size fractions the trends are more significant than for the $-38 \mu \mathrm{m}$ size fraction. This can be attributed to more pronounced magnetic flocculation for the $-75+53 \mu \mathrm{m}$ and $-53+38 \mu \mathrm{m}$ particle size suspensions, than for the $-38 \mu \mathrm{m}$ particle size fraction. Svoboda [19] has suggested that the tensile strength of the flocculated magnetite particles increases with particle sizes ranging from 10-60 $\mu \mathrm{m}$. To explain the effect of magnetic flocculation on sedimentation, it should be noted that an isolated particle of radius $b$ and magnetic susceptibility $\chi$ acquires a magnetic dipole $\mathbf{m}$ in the presence of an external magnetic field $(\mathbf{H})$.

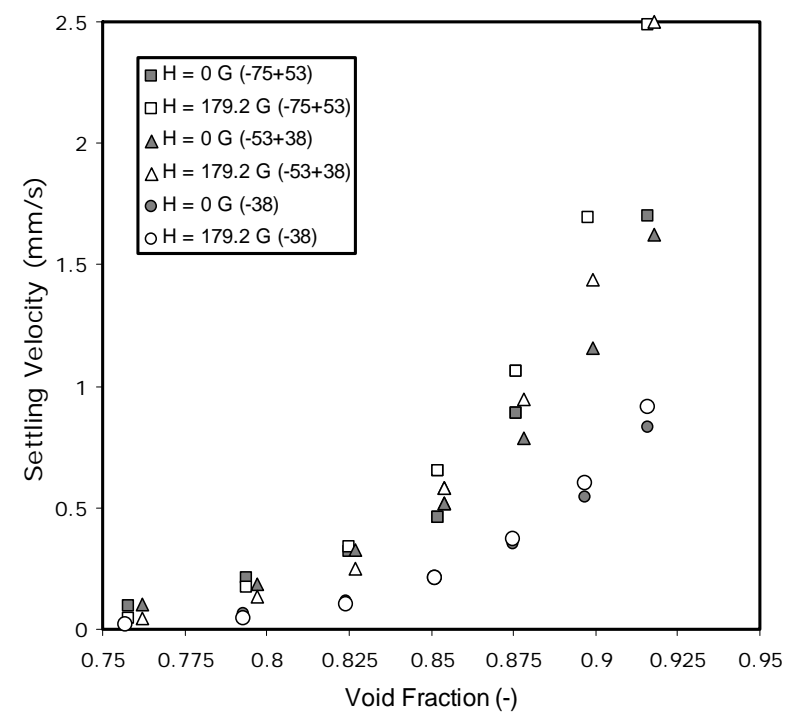

Fig. (8). Sedimentation velocity versus voidage (1- $\phi)$ for different particle size fractions (square $=-75+53 \mu \mathrm{m}$, triangle $=-53+38 \mu \mathrm{m}$, circle $=-38 \mu \mathrm{m}$, ) in the absence (solid markers) and presence (empty markers). $\mathbf{m}=(4 / 3) \pi b^{3} \mu_{0} \chi \mathbf{H}$

In a suspension of identical spherical magnetic particles in an external magnetic field, the magnetic interaction between two particles separated by a distance $r$ is

$\mathrm{V}_{\mathrm{M}}=\left(1 / \mu_{0} \mathrm{r}^{3}\right)\left[\mathbf{m}_{1} \mathbf{m}_{2}-3\left(\mathbf{m}_{1} \mathrm{r}\right)\left(\mathbf{m}_{2} \mathrm{r}\right) \mathrm{r}^{-2}\right]$

Under certain assumptions, the expression for $\mathrm{V}_{\mathrm{M}}$ can be approximated as follows [18].

$\mathrm{V}_{\mathrm{M}}=-32 \pi^{2} \mathrm{~b}^{6} \chi^{2} \mathrm{~B}^{2} / 9 \mu_{0} \mathrm{r}^{3}$

Considering the repulsive interaction of the electric double layer

$\mathrm{V}_{\mathrm{R}}=\varepsilon b \psi_{0}^{2} \exp [-\tau(\mathrm{s}-2)] / \mathrm{s}$

and the London Van der Waals attractive interaction

$\mathrm{V}_{\mathrm{A}}=-(\mathrm{A} / 6)\left[2 /\left(\mathrm{s}^{2}-4\right)+2 / \mathrm{s}^{2}+\ln \left(\mathrm{s}^{2}-4\right) / \mathrm{s}^{2}\right]$

the total energy of interaction $\mathrm{V}_{\mathrm{T}}$ between two particles in the magnetized system is given by

$\mathrm{V}_{\mathrm{T}}=\mathrm{V}_{\mathrm{A}}+\mathrm{V}_{\mathrm{R}}+\mathrm{V}_{\mathrm{M}}$

Flocculation in the suspension depends on the value of $\mathrm{V}_{\mathrm{T}}$. Since magnetite is a ferromagnetic mineral, it remains magnetized or polarized after exposure to an external magnetic field. Moreover, the magnetic interaction between particles $\left(\mathrm{V}_{\mathrm{M}}\right)$ is much larger that the double layer interaction $\left(\mathrm{V}_{\mathrm{R}}\right)$ and the London-van der Waals interaction $\left(\mathrm{V}_{\mathrm{A}}\right)$, so that $V_{R}$ and $V_{A}$ can usually be neglected in comparison to $V_{M}$. This means that flocculation depends mostly on the magnetic interaction between particles, hence the observed differences in the settling behaviour of magnetized and non-magnetized suspensions. However, in suspensions containing finer particles, such as the $-38 \mu \mathrm{m}$ size fraction, the double layer interaction $\mathrm{V}_{\mathrm{R}}$ and the London-van der Waals interaction $\mathrm{V}_{\mathrm{A}}$ are comparable to or larger than the magnetic interaction $V_{M}$, so that magnetization plays a lesser role in the settling of these suspensions. Like the non-magnetized suspensions, the following correlation of sedimentation velocity versus voidage was found to hold: $U_{\phi}=K(1-\phi)^{n}$. The values of parameters $K$ and $\mathrm{n}$ for different size fractions and magnetic field strengths are summarized in Table 3. Assuming $\mathrm{K}$ to be the terminal velocity of the particles in finite fluids $U_{t}$, the settling of 
which obeys Stokes' law (eq. 10), $\mathrm{U}_{\mathrm{t} \infty}$ is first calculated by use of eq. 5, after which the Stokes diameter $\mathrm{d}_{\mathrm{St}}$ for different particle size fractions and magnetic field strengths could be obtained.

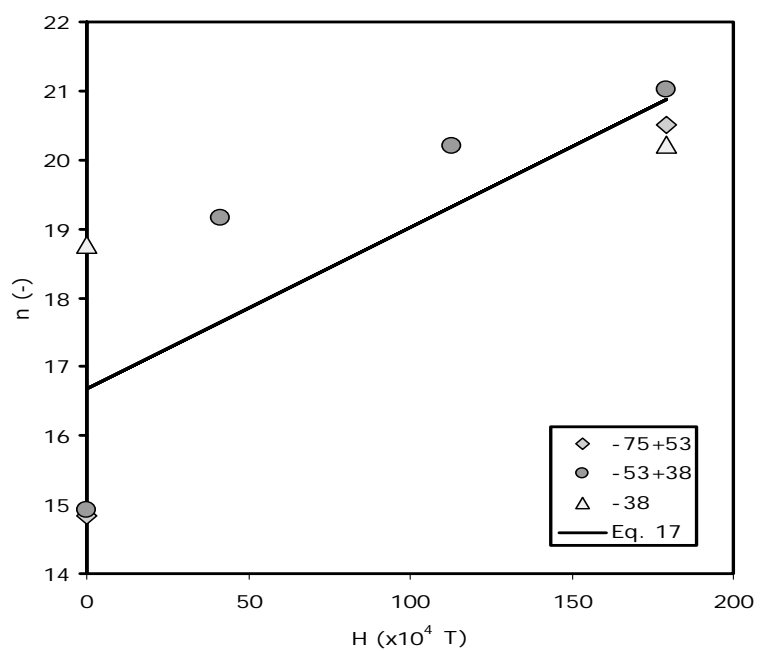

Fig. (9). Relationship between magnetic field strength $(\mathrm{H})$ and index n.

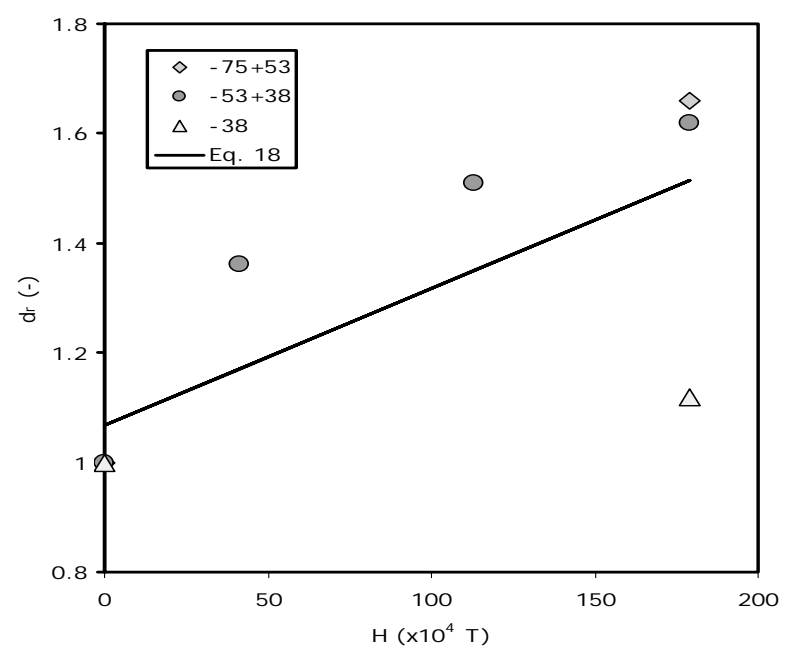

Fig. (10). Relationship between magnetic field strength $(\mathrm{H})$ and relative diameter $d_{r}$.
The Stokes diameter of the magnetic flocs $\left(\mathrm{d}_{\mathrm{Stf}}\right)$ and the relative diameter of the flocs $\mathrm{d}_{\mathrm{r}}\left(=\mathrm{d}_{\mathrm{St}} / \mathrm{d}_{\mathrm{St}}\right)$ are also summarized in Table 3. From Table $\mathbf{3}$ it can be seen that the values of $\mathrm{K}, \mathrm{d}_{\mathrm{St}}$ or $\mathrm{d}_{\mathrm{r}}$ increase as the magnetic field strength $\mathrm{H}$ increases. The correlation between the index $\mathrm{n}$ and the magnetic field $\mathrm{H}$ for all the particle size fractions collectively can be represented by the least squares fit in eq. 17, based on 8 observations and a squared correlation coefficient of $\mathrm{R}^{2}=$ 0.66 . The $95 \%$ confidence limits of the slope are $6.67 \times 10^{-3}$ and $4.03 \times 10^{-2}$.

$\mathrm{n}=2.35 \times 10^{-2} \mathrm{H}+16.7$

The fit indicates a marginal increase in $d_{r}$ with an increase in the magnetic field strength $\mathrm{H}$.

Likewise, the value of the relative diameter $d_{r}$ appears to increase slightly with an increase in the magnetic field strength $\mathrm{H}$ according to eq. 18, based on 8 observations and a squared correlation coefficient of $\mathrm{R}^{2}=0.55$. In this case the $95 \%$ confidence limits of the slope are $2.21 \times 10^{-4}$ and $4.76 \times$ $10^{-3}$.

$\mathrm{d}_{\mathrm{r}}=2.49 \times 10^{-3} \mathrm{H}+1.07$

Figs. (9) and (10) illustrate the fits of eq. 17 and 18 to the data. An increase in the value of index $n$ for magnetized suspensions means that the stability of these suspensions depends more strongly on concentration than that of the nonmagnetized suspensions. At low concentrations, the higher the magnetic field, the more unstable the suspensions are and conversely, at high concentrations, the higher the magnetic field, the more stable the suspensions.

\section{CONCLUSIONS}

For nonmagnetized magnetite, the correlations between sedimentation velocity and voidage derived from the experimental data agree well with the Richardson-Zaki equation (eq. 2). The values of the index $\mathrm{n}$ in the Richardson-Zaki equation calculated from the experimental data for nonspherical particles are considerably larger than those for spherical, and non- or weakly magnetic particles, in line with earlier observations by Chong et al. [21], Turney et al. [15] and Mercer et al. [22]. That is, the sedimentation behaviour of industrial suspensions with complicated shapes of particles is more dependent on the solid concentration.

Table 3. Properties of the Flocculated Magnetic Particles

\begin{tabular}{|c|c|c|c|c|c|c|}
\hline Size Frac $(\mu \mathbf{m})$ & $H\left(x 10^{4} T\right)$ & $\mathbf{K}(\mathbf{m m} / \mathbf{s})$ & n (-) & $\mathbf{d}_{\mathrm{st}}(\mu \mathbf{m})$ & $\mathbf{d}_{\mathrm{Stf}}(\mu \mathbf{m})$ & $\mathbf{d}_{\mathbf{r}}(-)$ \\
\hline$-75+53$ & 0 & 5.88 & 14.84 & 54.0 & 54.0 & 1 \\
\hline \multirow[t]{3}{*}{$-53+38$} & 0 & 5.61 & 14.92 & 52.1 & 52.1 & 1 \\
\hline & 41.2 & 10.30 & 19.16 & 52.1 & 70.6 & 1.36 \\
\hline & 179.2 & 14.64 & 21.02 & 52.1 & 84.2 & 1.62 \\
\hline \multirow[t]{2}{*}{-38} & 0 & 4.32 & 18.77 & 46.4 & 46.4 & 1 \\
\hline & 179.2 & 5.38 & 20.22 & 46.4 & 51.8 & 1.12 \\
\hline
\end{tabular}


The stabilities of magnetized magnetite suspensions are influenced more by solids concentration than those of nonmagnetized magnetite suspensions. At low concentrations ( $\phi$ $<0.15)$ the sedimentation velocity of magnetized suspensions is larger than that of non-magnetized ones. At high concentrations $(\phi \geq 0.15)$, magnetized suspensions settle more slowly than non-magnetized ones. However, owing to relatively weak magnetic interaction, the difference in the sedimentation rates of the magnetized and non-magnetized $38 \mu \mathrm{m}$ size fractions was less pronounced than for the larger size fractions. For magnetized suspensions, the correlations for settling also have the same form as the Richardson-Zaki equation. Both the Stokes diameters of the particles and the exponents in the Richardson Zaki models increased with an increase in the magnetic field strength $\mathrm{H}$.

\section{ACKNOWLEDGMENTS}

The National Accelerator Centre of South Africa is gratefully acknowledged for making available the electromagnetic field equipment used in the experiments.

\section{NOMENCLATURE}

\begin{tabular}{|c|c|c|}
\hline A & $=$ & Hamaker constant $(\mathrm{J})$ \\
\hline$b$ & $=$ & Particle radius $(\mathrm{m})$ \\
\hline 3 & $=$ & Magnetic induction (T) \\
\hline$C_{m}$ & $=$ & Maximum packing weight fraction of solid (-) \\
\hline & $=$ & Particle diameter $(\mathrm{m})$ \\
\hline nean & $=$ & The mean diameter calculated by eq. 7 (m) \\
\hline 50 & $=$ & $\begin{array}{l}\text { The particle diameter responding to cumulative } \\
\text { fraction of } 50 \%(\mathrm{~m})\end{array}$ \\
\hline $\mathrm{St}$ & $=$ & Stokes diameter $(\mathrm{m})$ \\
\hline$d_{\text {Stf }}$ & $=$ & Stokes diameter of flocculated particle (m) \\
\hline$d_{r}$ & $=$ & $\begin{array}{l}\text { Relative diameter of flocculated particle, }= \\
\mathrm{d}_{\mathrm{St}} / \mathrm{d}_{\mathrm{St}}(-)\end{array}$ \\
\hline 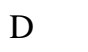 & $=$ & Diameter of measurement cylinder (m) \\
\hline $\mathrm{H}$ & $=$ & Magnetic field strength $(\mathrm{A} / \mathrm{m})$ \\
\hline $\mathrm{H}$ & $=$ & Magnetic field strength vector $(\mathrm{A} / \mathrm{m})$ \\
\hline & $=$ & Gravitational acceleration $\left(9.81 \mathrm{~m} / \mathrm{s}^{2}\right)$ \\
\hline $\mathrm{n}$ & $=$ & Magnetic dipole $\left(\mathrm{Am}^{2}\right)$ \\
\hline $\mathrm{n}$ & $=$ & Magnetic dipole vector $\left(\mathrm{Am}^{2}\right)$ \\
\hline & $=$ & Index in Richardson and Zaki equation (-) \\
\hline & $=$ & Interparticle distance $(\mathrm{m})$ \\
\hline $\operatorname{Re}$ & $=$ & Particle Reynolds number, $\rho U_{t} d / \eta(-)$ \\
\hline $\operatorname{Re}_{\infty}$ & $=$ & Particle Reynolds number, $\rho U_{\text {too }} \mathrm{d} / \eta(-)$ \\
\hline & $=$ & Normalized interparticle distance, $=\mathrm{r} / \mathrm{b}(-)$ \\
\hline $\mathrm{U}_{\mathrm{s}}$ & $=$ & $\begin{array}{l}\text { Slip velocity or relative velocity between par- } \\
\text { ticles and fluid }(\mathrm{m} / \mathrm{s})\end{array}$ \\
\hline $\mathrm{U}_{\phi}$ & $=$ & Settling velocity in suspension $(\mathrm{m} / \mathrm{s})$ \\
\hline $\mathrm{U}_{\mathrm{t}}$ & $=$ & $\begin{array}{l}\text { Terminal velocity of a single particle in finite } \\
\text { fluid }(\mathrm{m} / \mathrm{s})\end{array}$ \\
\hline $\mathrm{U}_{\mathrm{t} \infty}$ & $=$ & $\begin{array}{l}\text { Terminal velocity of a single particle in infinite } \\
\text { fluid }(\mathrm{m} / \mathrm{s})\end{array}$ \\
\hline
\end{tabular}

$\mathrm{U}_{\mathrm{t}, \exp }=$ Experimental terminal velocity of a single particle in finite fluid $(\mathrm{m} / \mathrm{s})$

$\mathrm{U}_{\mathrm{t}, \mathrm{calc}}=$ Calculated terminal velocity of a single particle in infinite fluid $(\mathrm{m} / \mathrm{s})$

$\mathrm{U}_{\mathrm{t}, \infty, \exp }=$ Experimental terminal velocity of a single particle in infinite fluid $(\mathrm{m} / \mathrm{s})$

$\mathrm{U}_{\mathrm{t}, \infty, \text { calc }}=$ Calculated terminal velocity of a single particle in infinite fluid $(\mathrm{m} / \mathrm{s})$

$\mathrm{V}_{\mathrm{A}}=$ London-van der Waals interaction

$\mathrm{V}_{\mathrm{R}}=$ Electric double-layer interaction

$\mathrm{V}_{\mathrm{M}}=$ Magnetic dipolar interaction

$\mathrm{V}_{\mathrm{T}}=$ Total interaction

$\phi \quad=\quad$ Volume fraction of solid (-)

$\phi_{\mathrm{m}} \quad=\quad$ Maximum packing volume (-)

$\kappa=$ Ratio of effective volume fraction of solid, including entrained liquid, to volume fraction of solid (-)

$\eta \quad=\quad$ Dynamic viscosity of fluid $(\mathrm{kg} / \mathrm{ms})$

$\rho \quad=\quad$ Density of fluid $\left(\mathrm{kg} / \mathrm{m}^{3}\right)$

$\rho_{\mathrm{s}} \quad=$ Density of solid $\left(\mathrm{kg} / \mathrm{m}^{3}\right)$

$\theta=$ Angle between the magnetic field and the line joining the centres of mass of particles

$\mu_{0}=$ Magnetic permeability of vacuum $(\mathrm{H} / \mathrm{m})$

$\tau==\xi \mathrm{b}$, where $\xi$ is the Debye-Huckel reciprocal length parameter (-)

$\psi_{0}=$ Potential at the surface of the particle (V)

$\varepsilon=$ Dielectric constant of fluid (-)

$\chi \quad=\quad$ Magnetic susceptibility of particle (-)

\section{REFERENCES}

[1] J. F. Richardson, and W. N. Zaki, "Sedimentation and fluidization: Part I", Trans. Inst. Chem. Eng., vol. 32, pp. 35-53, 1954.

[2] J. Garside, and M. R. Al-Dibouni, "Velocity-voidage relationship for fluidization and sedimentation in solid-liquid systems", Proc. Des. Dev., vol. 16, pp. 206-214, 1977.

[3] R. D. Felice, and E. Parodi, "Wall effects on the sedimentation velocity of suspensions in viscous flow", AIChE J., vol. 42, no 4, pp. 927-931, 1996.

[4] A. S. Michaels, and J. C. Bolger, "Settling rates and sediment volumes of flocculated kaolin suspensions", Ind. Eng. Chem. Fundam., vol. 1, pp. 24-33, 1962.

[5] R. M. Turian, F. Hsu, K. S. Avramidis, D. Sung, D, and R. K. Allendorfer, "Settling and rheology of suspensions of narrow-sized coal particles", AIChE J., vol. 38, no 7, pp. 969-987, 1992.

[6] S. Mirza, and J. F. Richardson, "Sedimentation of suspensions of particles of two or more sizes", Chem. Eng. Sci., vol. 34, no 4, pp. 447-454, 1979.

[7] M. S. Selim, A. C. Kothari, and R. M. Turian, "Sedimentation of multisized particles in concentrated suspensions", AIChE J., vol. 29, no. 6, pp. 1029-1038, 1983.

[8] V. S. Patwardhan, and C. Tien, "Sedimentation and liquid fluidization of solid particles of different sizes and densities", Chem. Eng. Sci., vol. 40, no. 7, pp. 1051-1060, 1985.

[9] R. H. Davis, and K. H. Birdsell, "Hindered settling of semidilute monodisperse and polydisperse suspensions", AIChE J., vol. 34, no. 1 , pp. $123-129,1988$.

[10] M. A. Al-Naafa, and M. S. Selim, "Sedimentation of polydisperse concentrated suspensions", Can. J. Chem. Eng., vol. 67, pp. 253264, 1989. 
[11] M.A. Al-Naafa, and M.S. Selim, Sedimentation of monodisperse and bidisperse hard-sphere colloidal suspensions, AIChE J., vol. 38(10), pp. 1618-1630, 1992.

[12] R. G. Cox, "Instability of sedimenting bidisperse suspensions", Int. J. Multiphase Flow, vol. 16, no. 4, pp. 617-638, 1990.

[13] R. H. Davis, and H. Gecol, "Hindered settling function with no empirical parameters for polydisperse suspensions", AIChE J., vol. 40, no. 3, pp. 570-575, 1994.

[14] F. M. Auzerais, R. Jackson, W. B. Russel, and W. F. Murphy, "The transient settling of stable and flocculated dispersions", J. Fluid Mech., vol. 221, pp. 613-639, 1990.

[15] A. M. Turney, M. K. Cheung, R. L. Powell, and M. J. McCarthy, "Hindered settling of rod-like particles measured with resonance imaging", AIChE J., vol. 41, no. 2, pp. 251-257, 1995.

[16] J. M. Vergouw, J. Anson, R. Dalhke, Z. Xu, C. Gomez, and J. A. Finch, "An automated data acquisition technique for settling tests", Min. Eng., vol. 10, no. 10, pp. 1095-1105, 1997.
[17] J. Svoboda, "A theoretical approach to the magnetic flocculation of weakly magnetic minerals", Int. J. Min. Proc., vol. 8, no. 4, pp. 377-390, 1981.

[18] J. Svoboda, "Magnetic flocculation and treatment of fine weakly magnetic minerals", IEEE Trans. Magn., vol. 18, no. 2, pp. 796801, 1982.

[19] J. Svoboda, "Development in Mineral Processing", Vol. 8: In Magnetic Methods for the Treatment of Minerals, Elsevier, The Netherlands, 1987.

[20] V. L. Ganzha, and S. C. Saxena, "Hydrodynamic behavior of magnetically stabilized fluidised beds of magnetic particles", Powder Technol., vol. 107, pp. 31-35, 2000.

[21] Y. B. Chong, D. A. Ratkowsky, and N. Epstein, "Effect of particle shape on hindered settling in creeping flow", Powder Technol., vol. 23, pp. 55-66, 1979.

[22] T. Mercer, P. R. Bissell, and R. G. Gilson, "Measurement of hindered settling in magnetic dispersions", IEEE Trans. Magn., vol. 38 , no. 5, pp. 3219-3221, 2002.

(C) Yang and Aldrich; Licensee Bentham Open.

This is an open access article licensed under the terms of the Creative Commons Attribution Non-Commercial License (http://creativecommons.org/licenses/by$\mathrm{nc} / 3.0 /$ ) which permits unrestricted, non-commercial use, distribution and reproduction in any medium, provided the work is properly cited. 